Article

\title{
Preparation, Characterization, and Biological Features of Cactus Coated Bacterial Cellulose Hydrogels
}

\author{
Tahseen Kamal ${ }^{1, *}$, Mazhar Ul-Islam ${ }^{2}{ }^{\mathbb{D}}$, Sher Bahadar Khan ${ }^{1} \mathbb{D}$, Esraa M. Bakhsh ${ }^{3}$ \\ and Muhammad Tariq Saeed Chani ${ }^{1}$ \\ 1 Center of Excellence for Advanced Materials Research, King Abdulaziz University, \\ Jeddah 21589, Saudi Arabia; sbkhan@kau.edu.sa (S.B.K.); mtmohamad@kau.edu.sa (M.T.S.C.) \\ 2 Department of Chemical Engineering, College of Engineering, Dhofar University, Salalah 211, Oman; \\ mulislam@du.edu.om \\ 3 Department of Chemistry, King Abdulaziz University, Jeddah 80200, Saudi Arabia; ibakhsh@kau.edu.sa \\ * Correspondence: tkkhan@kau.edu.sa
}

check for updates

Citation: Kamal, T.; Ul-Islam, M.; Khan, S.B.; Bakhsh, E.M.; Chani, M.T.S. Preparation, Characterization, and Biological Features of Cactus Coated Bacterial Cellulose Hydrogels. Gels 2022, 8, 88. https://doi.org/ $10.3390 /$ gels 8020088

Academic Editor: Claudia Tomasini

Received: 27 December 2021

Accepted: 26 January 2022

Published: 30 January 2022

Publisher's Note: MDPI stays neutral with regard to jurisdictional claims in published maps and institutional affiliations.

Copyright: (C) 2022 by the authors. Licensee MDPI, Basel, Switzerland. This article is an open access article distributed under the terms and conditions of the Creative Commons Attribution (CC BY) license (https:// creativecommons.org/licenses/by/ $4.0 /)$.

\begin{abstract}
The current study was aimed at developing BC-Cactus (BCC) composite hydrogels with impressive mechanical features for their potential applications in medical and environmental sectors. BCC composites hydrogels were developed through cactus gel coating on a never dried BC matrix. The FE-SEM micrographs confirmed the saturation of BC fibrils with cactus gel. Additionally, the presence of various functional groups and alteration in crystalline behavior was confirmed through FTIR and XRD analysis. Mechanical testing illustrated a three-times increase in the strain failure and an increase of 1.6 times in the tensile strength of BCC composite. Absorption capabilities of BCC were much higher than pure $\mathrm{BC}$ and it retained water for a longer period of time. Additionally, the rewetting and absorption potentials of composites were also higher than pure $\mathrm{BC}$. The composite efficiently adsorbed $\mathrm{Pb}, \mathrm{Zn}, \mathrm{Cu}$, and Co metals. Biocompatibility studies against human HaCat cell line indicated much better cell adhesion and proliferation of BCC compared to BC. These findings advocate that the BCC composite could find applications in medical, pharmaceutical and environmental fields.
\end{abstract}

Keywords: bacterial cellulose; adsorption; cactus composite; mechanical properties; biocompatibility

\section{Introduction}

Bacterial cellulose $(\mathrm{BC})$ is an organic polymer synthesized by a class of acetic acid producing bacterial strains [1]. Cell-free systems can also produce BC by using different sugar sources [2,3]. These cell free systems produce glucose chains, which self-aggregate and form protruding cellulose nanofibers [4]. These cellulose nanofibers give rise to a web-shaped three-dimensional nano-porous structure with a high surface area. The nano-porous geometry, hydrophilicity, and presence of hydroxyl groups make BC an excellent matrix for holding liquids [5]. In addition to this, the structural, mechanical, physico-chemical, and biological properties of $\mathrm{BC}$ has made it an important entity in biomedical [6,7], environmental [5], pharmaceutical [8,9], sensing [10], energy [11], and several other fields. Although BC has found its applications in varied sectors, due to its low mechanical strength and lack of adhesion sites, its application is restricted in many fields. Based on the background of $\mathrm{BC}$, the need to develop its composites with other materials to improve its existing features is of the upmost importance. Incorporation of $\mathrm{BC}$ with therapeutically active and biocompatible natural compounds/extracts has proved to be an effective approach towards the synthesis of $\mathrm{BC}$ composites with enhanced therapeutic potential and mechanical strength.

The cactus Opuntia (genus Opuntia, family Cactaceae) is a xerophytic plant. This plant is mainly grown in an arid and semi-arid region. Morphologically, Cactus plants are composed of flattened stems (cladodes), fruits and the areoles having minute-barbed spines, 
rudimentary leaves on new pads and seeds [12]. The vegetative part, frequently called as pads or cladodes are succulent and serves the purpose of water storage. Cactus plants are known to retain water due to high mucilage production in cladodes and fruits [13]. The epidermis of cladodes has two layers, the chlorenchyma (green cells), and an internal layer comprised of parenchyma (cylinder of white cells), which are mainly responsible for water storage. The chlorenchyma and parenchyma contain mucilaginous cells that store mucilage, which exhibits the osmotic property of strong water retention.

Opuntia spp. has been used traditionally in food and as well for medicinal purposes. Their extracts have been found to possess anti-inflammatory and analgesic properties [14] and exhibit hypoglycemic effects [15]. In addition to its medicinal properties, mucilage obtained from pads is a potential source of hydrocolloids, which are useful in cosmetic applications [12]. Some studies have reported its use in water purification or filtration [16]. Opuntia spp. extract is also reported to increase the plasticity and water absorption capacity of mortar [17].

In the present study, we have synthesized a composite of BC with Cactus pad extract through a simple coating technique. The aim was to enhance the BC existing mechanical, liquid holding and biocompatible features. The synthesis of BC-Cactus hydrogel was investigated through various analytical tools and its mechanical, adsorption and biocompatible activities were investigated against pure BC as control.

\section{Results and Discussion}

\subsection{Composite Synthesis and Characterization}

Among the number of strategies used to develop BC composites, the surface coating is preferred due to the fact that it retains the basic morphological features of $B C$ and augment it with additional ones coming from the functional coating. Materials addition in the BC production media for developing BC composites through in situ strategy can enhance the viscosity that, in turn, can retard the microbial activities and BC sheet formations [18]. BC composites with plant extracts, and gels including aloe vera hydrogel have been developed through ex-situ approaches [19]. The immersion of never dried BC sheets in liquid or semi liquid media offer ideal environment for solution and gels to attach to the fibril surface along with impregnating in the porous BC matrix. The BCC composite synthesis process through surface coating strategy has been illustrated in Figure 1.

(a)
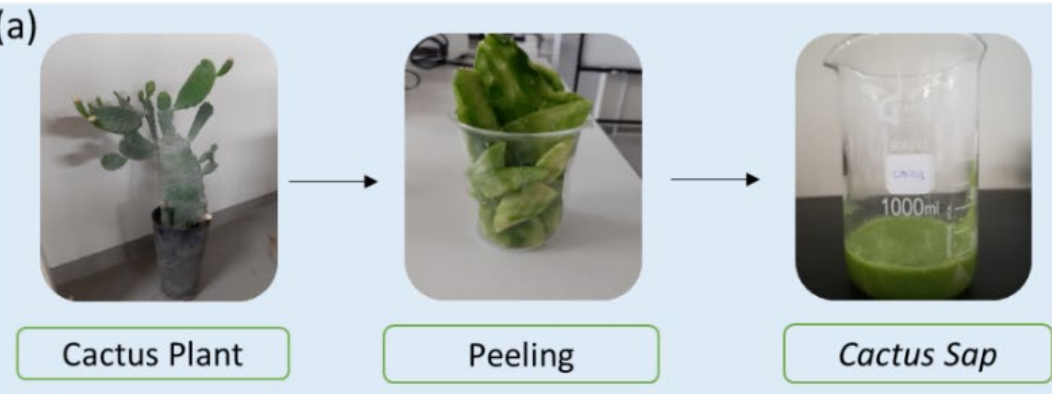

(b)
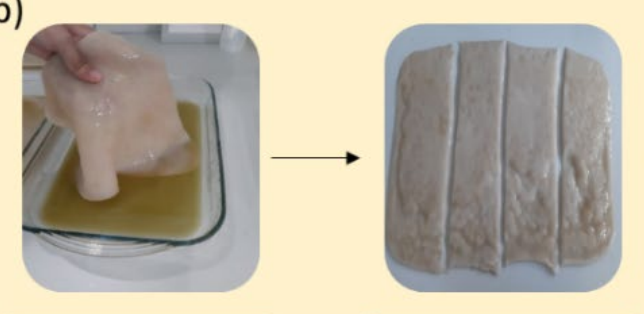

(c)

BC Sheet BC Strips

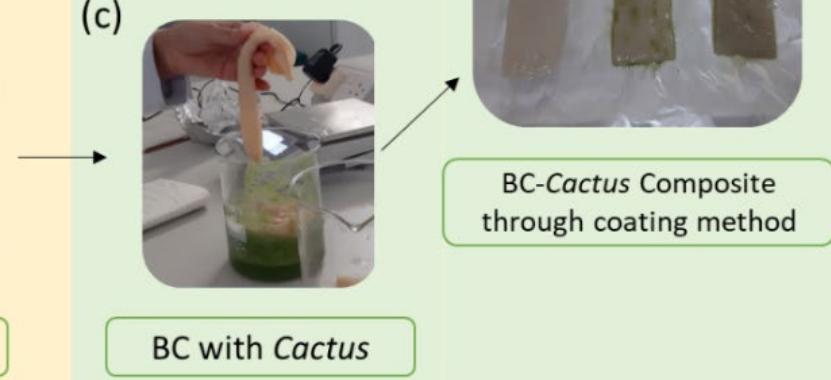

Figure 1. Different steps for the preparation of (a) cactus sap, (b) BC strips and (c) BCC composite. 
The morphology of BC after treatment with Cactus gel was observed through FE-SEM. The micrographs shown in Figure 2 indicate the porous fibril structure of BC. The thickness of fibril was below $100 \mathrm{~nm}$ and these were well arranged in 3D network form. While looking at the micrographs of BCC composite, it was clear that BC surface was covered by the Cactus gel. The porosity of native $\mathrm{BC}$ is much reduced. Hydroxyl moieties of BC offer an ideal situation for the attachment of various compounds to $\mathrm{BC}$ fibers through hydrogen bonding interactions. Strong attachment and covering of BC surface by Cactus is expected to affect its phytochemical and mechanical properties.
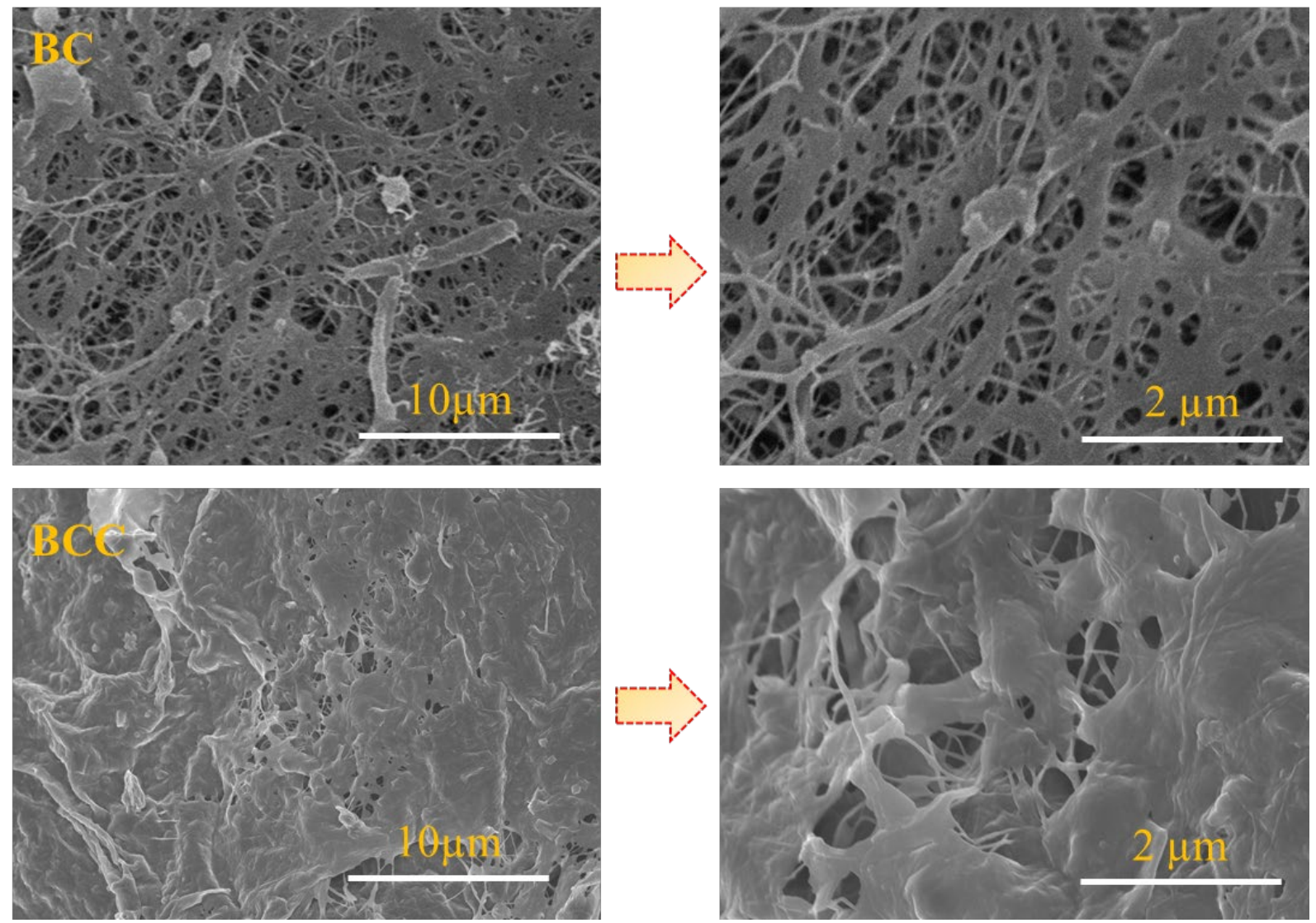

Figure 2. Field-emission scanning electron micrographs of surface morphologies of pristine BC and BCC composites.

XRD is a significant tool to study the crystalline nature of pure compounds and structural modifications observed via developing their composites. XRD results of the $\mathrm{BC}$ and BCC composites are shown in Figure 3. Native BC is semi-crystalline polymer consisting of both crystalline and amorphous parts. BC normally represents two main crystallinic peaks appearing at $2 \theta 14.6^{\circ}$ and $22.7^{\circ}$ ) corresponding to the crystallo-graphic planes of (110) and (200), respectively, as apparent in the current study (Figure 3). Another small peak occasionally appears at $16.2^{\circ}$. An amorphous halo present at $2 \theta 19.6^{\circ}$ represents the amorphous part of the pure BC [20]. Depending upon the nature of additive, the $\mathrm{BC}$ composite illustrates additional crystallinic peaks as well as modification in BC own crystallinic peak intensities. The XRD spectra of BCC shown in Figure 3 did not indicate any additional peak that is based on the non-crystalline nature of Cactus. However, one can find the intensities of crystalline $\mathrm{BC}$ have reduced to some extent as compared to pure BC. This intern reflects that BCC have less crystallinity than BC, which support the finding of mechanical testing where a huge increase in the stretching behavior of BCC was observed. 


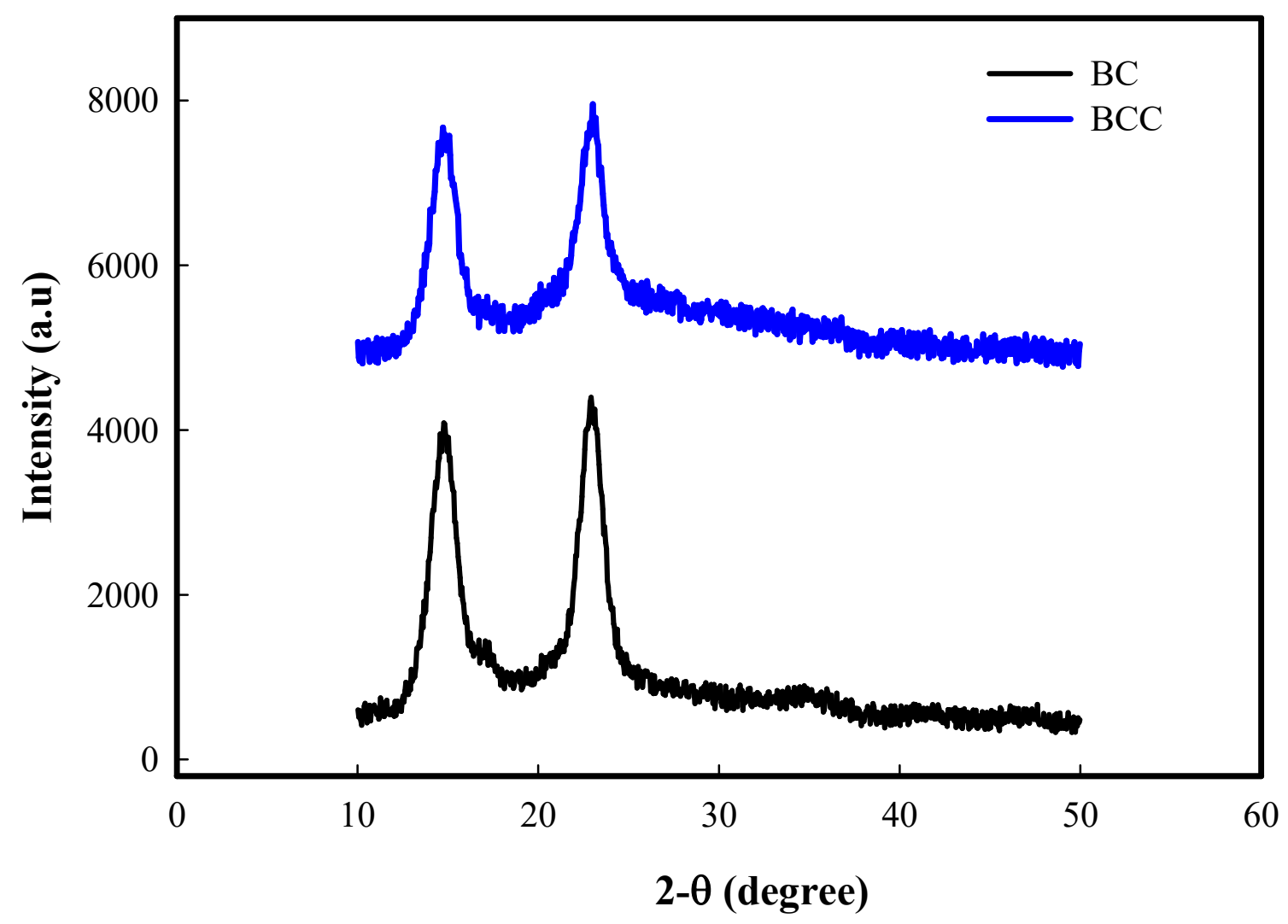

Figure 3. XRD analysis of BC, and BCC composite films.

\subsection{Mechanical Strength of BC and BCC Composite Hydrogel}

The tensile testing results for the pure BC and BCC are shown in Figure 4. Stressstrain curves for both samples move linearly toward their peak point and as the fracture started in the samples, the curves started to drop down. Stress-strain curves indicate that both samples are brittle in nature. Pure BC sample shows the maximum tensile strength of 54.14 MPa and failure strain of $9 \%$, by adding the Cactus coating on the pure $\mathrm{BC}$ its tensile strength and elongation properties increase as shown for the BCC, which have a maximum strength and failure strain of $78.18 \mathrm{MPa}$ and $26.52 \%$, respectively, as shown in Figure 5. Tensile strength of the BCC sample increase by 1.5 times and failure strain three times compared to the pure BC sample. Young's modulus of the BCC sample is $0.4 \mathrm{MPa}$, which is less than the Young's modulus of BC that is $0.6 \mathrm{MPa}$. Overall mechanical properties of pure $\mathrm{BC}$ are increased by impregnating cactus gel in its structure. The BC composites have been reported to show much higher mechanical features including tensile strength, modulus of elasticity or both depending upon the additives nature [21,22]. Cactus mechanical properties, specifically elastic features, are well explored. Some studies have reported very high modulus of elasticity (around $30 \mathrm{GPa}$ ) obtained with dry and wet cactus spines [23]. Developing BCC through such approach not only protects the existing strength of BC, but also improves its strength [18]. Earlier development of BC composites with graphene oxide has depicted an increase in mechanical strength [24]. In situ composites on the other hand interfere with BC fibril structure during the synthetic process, which can cause a reduction in its mechanical, crystalline and physiological features. It is expected that BCC composites with high elastic feature can find impressive applications in medical, cosmetics textile and other fields. 


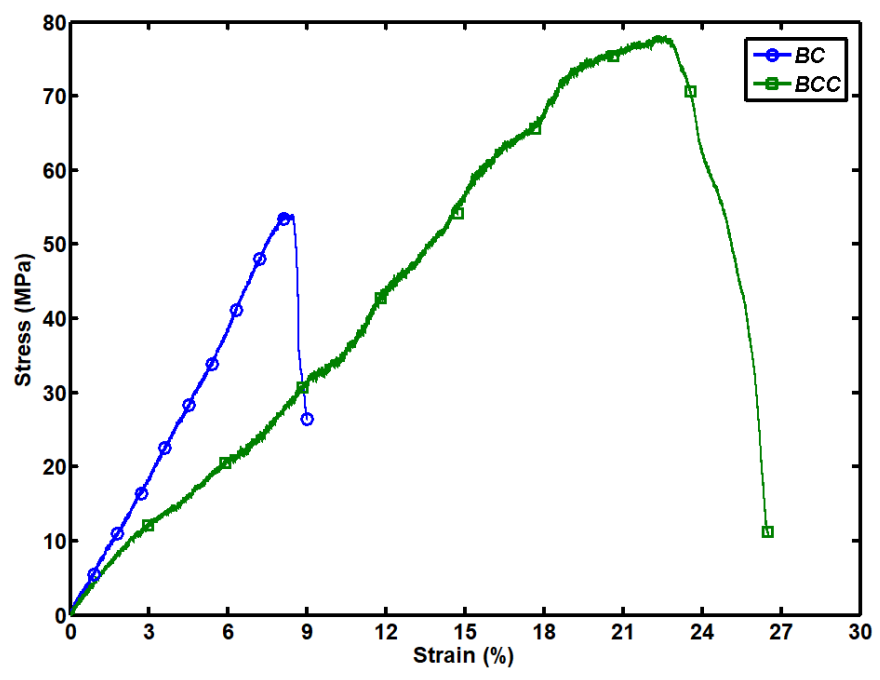

Figure 4. Stress-strain curve of pristine BC and BCC composite.

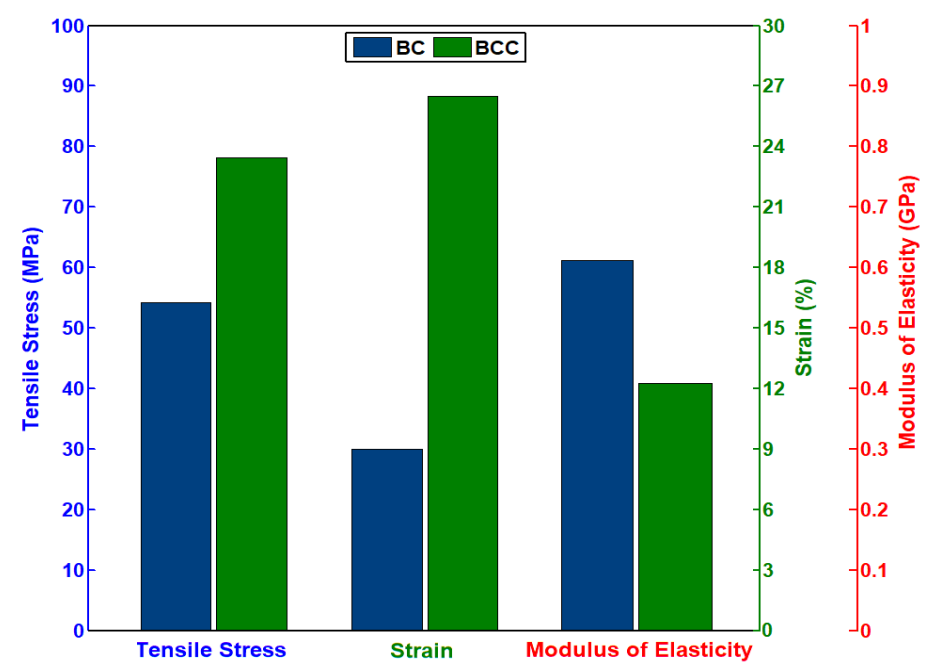

Figure 5. Tensile strength, strain (\%), and modulus of elasticity of BC and BCC composite.

\subsection{Absorption Studies}

High porosity and hydrophilic nature bless BC with remarkable absorbing capabilities. $\mathrm{BC}$ and its composite applications in medical fields are mainly built on its high absorbing capabilities besides its nontoxic and biocompatible nature [1]. It has been well established that never dried BC may absorb water over 100 times of its weight. Pore size and volume of $\mathrm{BC}$ indeed play vital role in defining the liquid holding capacities of BC samples. It has been reported that never dried BC has very high porosity and similarly high WHC. During drying process, the removal of surface water leads to the pore closure and conversion of reversible hydrogen bindings to irreversible hydrogen bindings. Therefore, we observed that water holding capabilities of dried and re-swelled BC are always less than never dried $\mathrm{BC}$ sheets. Another important aspect we observed is that freeze-dried BC results in better porosity than air-dried BC [25]. Water holding and retention capabilities of BC and BCC indicated in Figure 6A illustrated that pure BC hold around 109 times water of its dry weight compared to BCC, which could hold around 94 times. These results supported the SEM observation that cactus gel impregnated in BC network had reduced the porosity to some extent. While considering the water retention time of both $\mathrm{BC}$ and $\mathrm{BCC}$, it was observed that $\mathrm{BCC}$ could retain water for a longer time compared to pure $\mathrm{BC}$. Figure $6 \mathrm{~B}$ illustrates that water lost from $B C$ was much quicker and the curve was much more linear until almost a complete loss of water. BCC on other hand indicated reduced trends of water loss and retained a reasonable quantity of water until the extended time frame of $70 \mathrm{~h}$. The 
slow release could be attributed to the interaction of cactus gel with bonded water and relatively lower porosity of $\mathrm{BC}$ composites that hindered the escape of water molecules. The extension of WHC analysis in repeated batches of the same samples indicated that every time the WHC values were reduced to a great extent, around 30\% reduction in WHC was observed in between the never dried and 1st dried and re-swelled samples. The WHC kept on reducing with every drying and re-swelling cycle, however, it was important to observe that even after the fifth re-swelling cycle process, BC and BCC were able to hold more than $20 \%$ water of their dry weight. High WHC and slow WRR from BCC hydrogels are significant features for their applicability in medical and environmental fields [26,27].
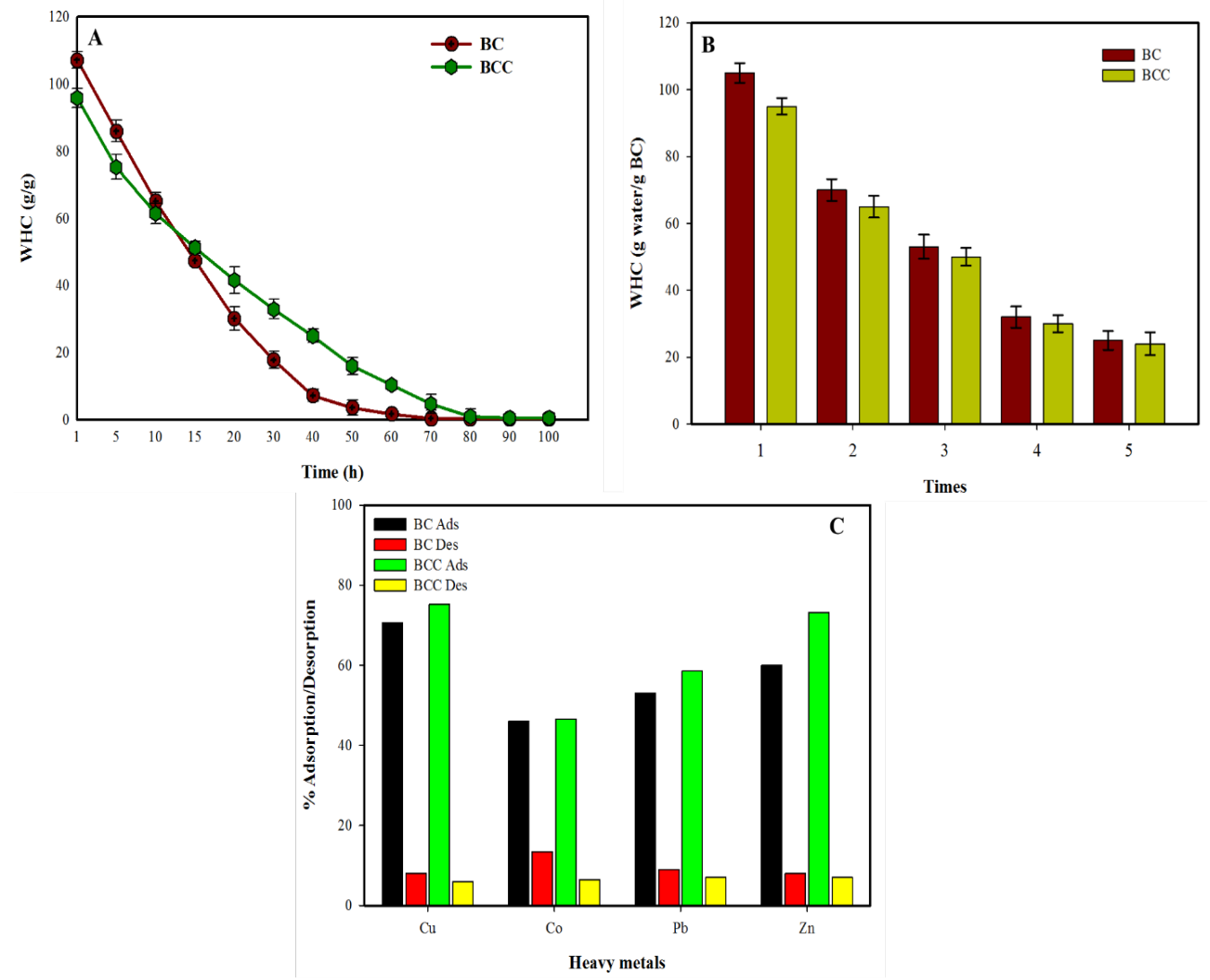

Figure 6. Absorption analysis of BC and BCC, (A) Water holding capacity (B) WHC in repeated batches through drying and re-swelling processes, $(\mathbf{C})$ heavy metal absorption analysis.

The Nanofibrillar structure and porous geometry of $\mathrm{BC}$ significantly contribute to the absorption of heavy metals [28]. BC and BC composite-based filters have been developed for absorbing unwanted toxic materials from industrial effluents and wastewater. The results of heavy metal absorbing proficiencies of BC and BCC observed against Cobalt $(\mathrm{Co})$, Copper $(\mathrm{Cu})$, Lead $(\mathrm{Pb})$ and Zinc $(\mathrm{Zn})$ are shown in Figure 6C. The results indicated that both $\mathrm{BC}$ and $\mathrm{BCC}$ were able to absorb substantial amount of heavy metals from water. Overall BCC indicated better absorption capabilities compared to BC. The development of $\mathrm{BC}$ composites for heavy metal adsorption have been reported earlier. Several synthetic polymers including chitosan, polyethylene glycol, attapulgite and other polymers for removal of $\mathrm{Cu}, \mathrm{Pb}, \mathrm{Cr}$ and other heavy metals. The use of natural materials like cactus gel for such applications have been rarely explored. Considering the exceptional mechanical, absorbing, and heavy metal removal feasibilities, it can be stated that BC composites with natural polymers and other compounds could be of vital importance in medical and environmental applications. 


\section{Conclusions}

BC composites with cactus gel (BCC) were successfully developed by impregnating cactus gel in a never dried BC matrix. Structural analysis indicated the formation of a cactus layer on the BC surface, whereas the bonding and crystalline features were further validated through FTIR and XRD studies. BCC composite illustrated much higher mechanical strength and three times higher modulus of elasticity. The biocompatibility evaluation against human $\mathrm{HaCat}$ cells showed much better cell attachment and proliferation abilities on the BCC surface. Additionally, the composite exhibited longer liquid retention capabilities along with better heavy metal absorption proportions. It can be concluded that the developed BCC composites with advanced biocompatible, mechanical, and absorption features could be used for applications in biomedical, pharmaceutical, and environment fields.

\section{Experimentation}

\subsection{Microbial Cell Culture and BC Production}

Gluconacetobacter hansenii was used as a BC-producing strain. This research followed an established protocol [31] for the cell culture and BC production.

\subsection{Production of BCC}

Opuntia spp. (Cactus) plants were collected from Salalah, Oman. The mature fresh pads or cladodes were cut from the plants and washed with water to remove dust. The thick epidermis of cladodes was gently peeled and inner parenchymous cells were crushed to collect the semi-solid mucilaginous content and kept in a sterile beaker. After that, BC and Cactus (BCC) hydrogel composite were prepared by dipping the BC sheets in Cactus gel for 2-3 days, as a result of which the gel was adsorbed on the surface and internal matrix of BC samples. The Cactus semi-solid gel-loaded BC (BC-Cactus or BCC) samples were separated from the beaker, gently cleaned, and stored for further use.

\subsection{Characterization}

The morphology of BC and BCC composite was observed through Field Emission Scanning electron microscope FE-SEM analysis (Hitachi S-4800 \& EDX-350, Horiba, Tokyo, Japan). Briefly, the samples were fixed onto a brass holder and coated with osmium tetroxide $\left(\mathrm{OsO}_{4}\right)$ by a VD HPC-ISW osmium coater (Tokyo, Japan) for FE-SEM observation. XRD patterns of BC and BCC composite film were recorded at $40 \mathrm{Kv}$ by an X-Ray diffractometer (X'Pert-APD PHILIPS, Almelo, the Netherlands) using $\mathrm{Cu} \mathrm{K} \alpha$ radiation.

\subsection{Mechanical Testing}

To perform the tensile testing, straight-sided samples having dimensions of $200 \mathrm{~mm} \times 25 \mathrm{~mm} \times 1 \mathrm{~mm}$ were cut from the air-dried composite sheets of BC and BCC. To prevent compression damages in the jaws of tensile testing machine, aluminum rectangular plates $(50 \mathrm{~mm} \times 25 \mathrm{~mm}$ ) were glued at both ends of the samples. Several quasi-static tensile tests were performed on the BC and BCC samples to compare their mechanical properties. Tensile tests were performed using Instron 8801 servo-hydraulic machine (Norwood, MA, USA) having load cell of $100 \mathrm{kN}$ capacity. Bluehill3 software was used to control the tensile testing machine's parameters such as loading rate. All the tests were performed at a loading rate of $1 \mathrm{~mm} / \mathrm{min}$ at ambient conditions and tensile load was applied on samples until their complete failure. To check the accuracy and repetition of the experimental results, for each case three tests were conducted, and test data is the average of these three test readings.

\subsection{Water Holding and Release Experiments}

The water retention time (WRT) and water holding capacity (WHC) experiments were performed for the BCC composites and BC following the reported method [32]. BC and BCC sheets were cut into rectangular pieces $\left(15 \mathrm{~cm}^{2}\right)$ and freeze-dried. The freeze-dried samples were weighed and placed in water under ambient temperature for several hrs. 
After complete wetting (receiving stabilized wet weight), the water retention capabilities of all samples were observed via measuring their weights at varying time intervals until reaching the complete dry state. The WHC was determined by the following formula [32]:

$$
\mathrm{WHC}=\frac{\text { Water content removed during drying }(\mathrm{g})}{\text { Dry weight of the sample }(\mathrm{g})}
$$

\subsection{Heavy Metal Absorption}

In order to perform the metal absorption study, different metal salt solutions including $\mathrm{Zn}\left(\mathrm{NO}_{3}\right)_{2},\left(\mathrm{Cu}\left(\mathrm{NO}_{3}\right)_{2}, \mathrm{Fe}\left(\mathrm{NO}_{3}\right)_{3}\right.$ and $\mathrm{Co}\left(\mathrm{NO}_{3}\right)_{2}$ were prepared in a deionized water, each with a concentration of $10 \mathrm{mg} / \mathrm{L}(10 \mathrm{ppm})$. Freeze-dried BC and BCC composites sheets were cut into small pieces of equal size and added into beakers having $200 \mathrm{~mL}$ of metal salt solution. Solutions were stirred at $200 \mathrm{rpm}$ for $24 \mathrm{~h}$ at $25^{\circ} \mathrm{C}$ in shaker. Thereafter, an atomic absorption spectrophotometer (AAS, PinAAcle 500, MedTech Park, Singapore) was used to measure the residual metal ion concentration by analyzing the $10 \mathrm{~mL}$ solution from every beaker. For desorption studies, the sheets were removed from the metal salt solutions and gently washed. Then each sample was placed overnight in a flask having $200 \mathrm{~mL}$ of distilled water under gentle shaking condition at room temperature. Finally, the above-mentioned protocol was followed for analyzing the desorbed metal ion concentrations.

\subsection{Invitro-Biocompatibility Determination}

Dulbecco's Modified Eagle's Medium (DMEM) was used for the culturing of HaCaT cells in $5 \% \mathrm{CO}_{2}$ at $37^{\circ} \mathrm{C}$. In order to determine cell viability on scaffolds (BC and BCC) were trimmed to round pieces of approximately $20 \mathrm{~mm}$ diameter and sterilized under UV. The samples were then seeded with the HaCaT cells at the density of $1.6 \times 10^{4}$ cells / scaffold (BC and BCC) in 12 well plates each having $1 \mathrm{~mL}$ of DMEM and incubated for $24 \mathrm{~h}$. The cells seeded on bacterial cellulose were used as a control. The proliferation and cell adhesion were measured using phase contrast microscopic analysis after $48 \mathrm{~h}$ of incubation.

\subsection{Viability Assay of HaCaT}

The 3-(4,5-dimethylthiazol-2-yl)-2,5diphenyltetrazolium bromide (MTT) assay was performed to check cell viability on fabricated scaffolds, each scaffold (BC and BCC) of $20 \mathrm{~mm}$ diameter was sterilized and then seeded with $\mathrm{HaCaT}$ at the density of $4 \times 10^{4}$ cells per scaffolds in 12 well micro titer plate for 1 and 2 days. After the incubation period, samples were rinsed with PBS to remove extra media and unattached cells. $0.5 \mathrm{mg} / \mathrm{mL}$ of MTT was added to each well and incubated for an extra $4 \mathrm{~h}$. Extra MTT solution was discarded and dimethyl sulphoxide (DMSO) (200 microliter/scaffold) was added to dissolve the formazan crystals. The optical density values of formazan solution were measured by a microplate reader (Molecular Devices, San Jose, CA, USA) at $540 \mathrm{~nm}$. The cells culture on BC served as control.

Author Contributions: Conceptualization, M.U.-I. and T.K.; methodology, M.U.-I.; software, M.U.-I.; validation, M.U.-I. and T.K.; formal analysis, M.U.-I.; investigation, M.U.-I.; resources, M.U.-I.; data curation, M.U.-I. writing-original draft preparation, M.U.-I. and T.K.; writing-review and editing, M.U.-I., T.K., S.B.K., E.M.B. and M.T.S.C.; supervision, M.U.-I.; project administration, T.K. and M.T.S.C.; funding acquisition, T.K. and M.T.S.C. All authors have read and agreed to the published version of the manuscript.

Funding: The authors extend their appreciation to the Deputyship for Research \& Innovation, Ministry of Education in Saudi Arabia for funding this research work through the project number (IFPNC-010-141-2020) and King Abdulaziz University, DSR, Jeddah, Saudi Arabia.

Institutional Review Board Statement: Not applicable.

Informed Consent Statement: Not applicable. 
Data Availability Statement: The data presented in this study are available from the corresponding author on request.

Conflicts of Interest: The authors declare no conflict of interest.

\section{References}

1. Ullah, M.W.; Manan, S.; Kiprono, S.J.; Ul-Islam, M.; Yang, G. Synthesis, structure, and properties of bacterial cellulose. In Nanocellulose: From Fundamentals to Advanced Materials, 1st ed.; Huang, J., Dufresne, A., Lin, N., Eds.; Wiley VCH: Weinheim, Germany, 2019; pp. 81-113.

2. Wajid Ullah, M.; Ul-Islam, M.; Khan, S.; Kim, Y.; Kon Park, J. Innovative production of bio-cellulose using a cell-free system derived from a single cell line. Carbohydr. Polym. 2015, 132, 286-294. [CrossRef] [PubMed]

3. Kim, Y.; Ullah, M.W.; Ul-Islam, M.; Khan, S.; Jang, J.H.; Park, J.K. Self-assembly of bio-cellulose nanofibrils through intermediate phase in a cell-free enzyme system. Biochem. Eng. J. 2019, 142, 135-144. [CrossRef]

4. Ullah, M.W.; Islam, M.U.; Khan, S.; Shah, N.; Park, J.K. Recent advancements in bioreactions of cellular and cell-free systems: A study of bacterial cellulose as a model. Korean J. Chem. Eng. 2017, 34, 1591-1599. [CrossRef]

5. Ul-Islam, M.; Ullah, M.W.; Khan, S.; Kamal, T.; Ul-Islam, S.; Shah, N.; Park, J.K. Recent advancement in cellulose based nanocomposite for addressing environmental challenges. Recent Pat. Nanotechnol. 2016, 10, 169-180. [CrossRef]

6. Curvello, R.; Raghuwanshi, V.S.; Garnier, G. Engineering nanocellulose hydrogels for biomedical applications. Adv. Colloid Interface Sci. 2019, 267, 47-61. [CrossRef]

7. Eslahi, N.; Mahmoodi, A.; Mahmoudi, N.; Zandi, N.; Simchi, A. Processing and properties of nanofibrous bacterial cellulosecontaining polymer composites: A review of recent advances for biomedical applications processing and properties of nanofibrous bacterial cellulose-containing polymer composites. Polym. Rev. 2019, 60, 144-170. [CrossRef]

8. Li, S.; Jasim, A.; Zhao, W.; Fu, L.; Ullah, M.W.; Shi, Z.; Yang, G. Fabrication of pH-electroactive bacterial cellulose / polyaniline hydrogel for the development of a controlled drug release system. ES Mater. Manuf. 2018, 1, 41-49. [CrossRef]

9. Ullah, H.; Wahid, F.; Santos, H.A.; Khan, T. Advances in biomedical and pharmaceutical applications of functional bacterial cellulose-based nanocomposites. Carbohydr. Polym. 2016, 150, 330-352. [CrossRef]

10. Farooq, U.; Ullah, M.W.; Yang, Q.; Aziz, A.; Xu, J.; Zhou, L.; Wang, S. High-density phage particles immobilization in surfacemodified bacterial cellulose for ultra-sensitive and selective electrochemical detection of Staphylococcus aureus. Biosens. Bioelectron. 2020, 157, 112163. [CrossRef]

11. Bu, Y.; Cao, M.; Jiang, Y.; Gao, L.; Shi, Z.; Xiao, X.; Wang, M.; Yang, G.; Zhou, Y.; Shen, Y. Ultra-thin bacterial cellulose / poly (Ethylenedioxythiophene) nanofibers paper electrodes for all-solid-state flexible supercapacitors. Electrochim. Acta 2018, 271, 624-631. [CrossRef]

12. Sáenz-Hernández, C.; Corrales-García, J.; Aquino-Pérez, G. Nopalitos, Mucilage, fiber, and cochineal. In Cacti: Biology and Uses; University of California Press: Berkeley, CA, USA, 2002.

13. Sáenz, C.; Sepúlveda, E.; Matsuhiro, B. Opuntia Spp. Mucilage's: A functional component with industrial perspectives. J. Arid Environ. 2004, 57, 275-290. [CrossRef]

14. Loro, J.F.; del Rio, I.; Perez-Santana, L. Preliminary studies of analgesic and anti-inflammatory properties of Opuntia dillenii aqueous extract. J. Ethnopharmacol. 1999, 67, 213-218. [CrossRef]

15. Andrade-Cetto, A.; Heinrich, M. Mexican plants with hypoglycaemic effect used in the treatment of diabetes. J. Ethnopharmacol. 2005, 99, 325-348. [CrossRef] [PubMed]

16. Pichler, T.; Young, K.; Alcantar, N. Eliminating turbidity in drinking water using the mucilage of a common cactus. Water Supply 2012, 12, 179-186. [CrossRef]

17. Chandra, S.; Eklund, L.; Villarreal, R.R. Use of cactus in mortars and concrete. Cem. Concr. Res. 1998, 28, 41-51. [CrossRef]

18. Ul-Islam, M.; Ahmad, F.; Fatima, A.; Shah, N.; Yasir, S.; Ahmad, W.; Manan, S.; Ullah, M.W. Ex situ synthesis and characterization of high strength multipurpose bacterial cellulose-aloe vera hydrogels. Front. Bioeng. Biotechnol. 2021, 9, 601988. [CrossRef]

19. Liu, W.; Du, H.; Zhang, M.; Liu, K.; Liu, H.; Xie, H.; Zhang, X.; Si, C. Bacterial cellulose-based composite scaffolds for biomedical applications: A review. ACS Sustain. Chem. Eng. 2020, 8, 7536-7562. [CrossRef]

20. Castro, C.; Zuluaga, R.; Putaux, J.-L.; Caro, G.; Mondragon, I.; Gañán, P. Structural characterization of bacterial cellulose produced by Gluconacetobacter swingsii sp. from colombian agroindustrial wastes. Carbohydr. Polym. 2011, 84, 96-102. [CrossRef]

21. Gabr, M.H.; Elrahman, M.A.; Okubo, K.; Fujii, T. A study on mechanical properties of bacterial cellulose / epoxy reinforced by plain woven carbon fiber modified with liquid rubber. Compos. Part Appl. Sci. Manuf. 2010, 41, 1263-1271. [CrossRef]

22. Indrarti, L.; Indriyati; Syampurwadi, A.; Pujiastuti, S. Physical and mechanical properties of modified bacterial cellulose composite films. AIP Conf. Proc. 2016, 1711, 050007. [CrossRef]

23. Gindl-Altmutter, W.; Keckes, J. The structure and mechanical properties of spines from the cactus opuntia ficus-indica. BioResources 2012, 7, 1232-1237. [CrossRef]

24. Kiangkitiwan, N.; Srikulkit, K. Preparation and properties of bacterial cellulose / graphene oxide composite films using dyeing method. Polym. Eng. Sci. 2021, 61, 1854-1863. [CrossRef]

25. Ul-Islam, M.; Khattak, W.A.; Kang, M.; Kim, S.M.; Khan, T.; Park, J.K. Effect of post-synthetic processing conditions on structural variations and applications of bacterial cellulose. Cellulose 2013, 20, 253-263. [CrossRef] 
26. Lin, D.; Liu, Z.; Shen, R.; Chen, S.; Yang, X. Bacterial cellulose in food industry: Current research and future prospects. Int. J. Biol. Macromol. 2020, 158, 1007-1019. [CrossRef] [PubMed]

27. Corzo Salinas, D.R.; Sordelli, A.; Martínez, L.A.; Villoldo, G.; Bernal, C.; Pérez, M.S.; Cerrutti, P.; Foresti, M.L. Production of bacterial cellulose tubes for biomedical applications: Analysis of the effect of fermentation time on selected properties. Int. J. Biol. Macromol. 2021, 189, 1-10. [CrossRef] [PubMed]

28. Jin, X.; Xiang, Z.; Liu, Q.; Chen, Y.; Lu, F. Polyethyleneimine-bacterial cellulose bioadsorbent for effective removal of copper and lead ions from aqueous solution. Bioresour. Technol. 2017, 244, 844-849. [CrossRef] [PubMed]

29. Dincă, V.; Mocanu, A.; Isopencu, G.; Busuioc, C.; Brajnicov, S.; Vlad, A.; Icriverzi, M.; Roseanu, A.; Dinescu, M.; Stroescu, M.; et al. Biocompatible pure $\mathrm{ZnO}$ nanoparticles-3D bacterial cellulose biointerfaces with antibacterial properties. Arab. J. Chem. 2020, 13, 3521-3533. [CrossRef]

30. Zhang, Z.-Y.; Sun, Y.; Zheng, Y.-D.; He, W.; Yang, Y.-Y.; Xie, Y.-J.; Feng, Z.-X.; Qiao, K. A Biocompatible bacterial cellulose / tannic acid composite with antibacterial and anti-biofilm activities for biomedical applications. Mater. Sci. Eng. C 2020, 106, 110249. [CrossRef] [PubMed]

31. Ul-Islam, M.; Khattak, W.A.; Ullah, M.W.; Khan, S.; Park, J.K. Synthesis of regenerated bacterial cellulose-zinc oxide nanocomposite films for biomedical applications. Cellulose 2014, 21, 433-447. [CrossRef]

32. Ul-Islam, M.; Khan, T.; Park, J.K. Water holding and release properties of bacterial cellulose obtained by in situ and ex situ modification. Carbohydr. Polym. 2012, 88, 596-603. [CrossRef] 